\title{
Innovation Relationships in the Emergence of Fintech Ecosystems
}

\author{
Kaisa Still \\ VTT Technical Research Centre \\ of Finland Ltd \\ kaisa.still@vtt.fi
}

\begin{abstract}
This paper explores the emergence of ecosystems in the context of Fintechs infusing digital technology into financial services. The rapid rise of Fintechs has changed the business landscape, challenging the established firms with novel solutions and services. As a result, the established firms are turning to new models of cooperation, replacing the hierarchically managed value chains with ecosystems that are modular and decentralized in their architecture. First, a bibliometric analysis was conducted to present the content and relationships in Fintech research in general. Then, a case study on two of the biggest retail banks in Finland and their innovation relationships in developing Distributed Ledger Technologies and related services was conducted. The results show how established players have established multiple innovation relationships, in different ecosystems as well as between them. These can be seen to demonstrate the emergence of Fintech ecosystems. The study contributes to previous literature by making the linkages explicit, particularly by examining the contextual elements that are crucial enablers or hindering factors in such relationships.
\end{abstract}

\section{Introduction}

Fintech is an acronym of words financial technology referring to the connection of modern technologies with established financial services [5]. In financial sector, established players have been slow in innovation activities. Thus, Fintech (with alternative spellings of Fintech, and fin tech) firms are able to challenge the established roles, business models, and service offerings in the financial sector with the introduction of technology-based innovations [7]. However, also established financial institutions must be regarded as a driving force in the Fintech development based on their role in a wider scope of ecosystems and platform economies such as funding and partnerships.

\author{
Marko Seppänen \\ Tampere University of Technology \\ marko.seppanen@tut.fi
}

The context of our paper is about the transformative power of digital technology in banking, financial and insurance. Technology developments have transformed banks' business landscape [8] and they are turning into new models of cooperation, replacing the hierarchically managed value chains with ecosystems that are modular and decentralized in their architecture [10].

The term ecosystem is widely used to describe the interdependencies and possibilities for novel value creation. Moore [15] defined the business ecosystem as follows: "companies coevolve capabilities around a new innovation: they work cooperatively and competitively to support new products, satisfy customer needs, and eventually incorporate the next round of innovations." The prefix eco (in relation to system) emphasizes the non-linear nature of innovation and the key role of collaboration in generating it [31].

Much of the ecosystem literature has concentrated on understanding what ecosystems are and how they operate [10]; comparatively few studies have been conducted to understand when and why ecosystems emerge. Little theoretical understanding exists on how ecosystems develop and evolve or how innovation can be addressed in multiple levels [1]. Furthermore, much of previous literature keeps the different forms of ecosystems separate. In the present study, we address this gap by focusing on the importance of innovation relationships for the emergence of ecosystems.

We explore the key terms as well as innovation relationships between various types of ecosystems, which have previously been approached by using multiscopic views or views on multiple ecosystem levels [27]. Our case example comes from the world of banking and finance-two of the largest retail banks in the Finnish market. We show how the innovation ecosystem is linked to the business ecosystem and the platform ecosystem. Accordingly, this study contributes to previous literature by making the linkages explicit, particularly by examining the contextual elements that are crucial enablers or hindering factors in such relationships. 
The paper is organized as follows. First, we explore previous research toward the understanding of the emergence of ecosystems. We explore the emergence of Fintech ecosystems by using a bibliometric approach to analyze the relationships within the Fintech research, and proceed to show how two of the largest retail banks in the Finnish market are connected to ecosystems that innovate and deliver distributed ledger technology based services. In the analyses, both qualitative and quantitative methods are used.

\section{Importance of innovation relationships}

Driven by global forces of non-linear innovation, the modern systems of production and economic governance are also acquiring a nonlinear structure and becoming decentralized, diffused, and dispersed along network nodes [25]. Based on these innovation relationships, a number of different types of ecosystems have been identified and explored, such as business ecosystems, software ecosystems, platform ecosystems, industrial ecosystems, digital business ecosystems, entrepreneurship ecosystems, and knowledge ecosystems, as well as start-up ecosystems, to name a few [16;28]. Ecosystems-as systems in general-are considered inherently dynamic; co-evolving ecosystem actors "develop over time sympathetically with the other participants in order to maintain [the] stability and health of the ecosystem in the face of change" [30]. Interactions between ecosystem actors are therefore needed, and through their manifestation as decisions and related actions, these relationships shape the present and future states of the ecosystem [32].

\subsection{Ambiguity of ecosystem concepts}

The value of the innovation ecosystem-or the value of the ecosystem concept, in general-has been criticized by scholars [19]. To address this conceptual ambiguity, a recent bibliographic analysis emphasizes the blurred boundaries and overlaps between innovation ecosystems, knowledge ecosystems, business ecosystems, and platforms [28]. It also shows that the ecosystem approach is clearly separated conceptually from traditional innovation system studies [28]. Further defense for ecosystem concept presents the links between micro and macro behaviors, as well as the competitive and cooperative actions of actors to support the ecosystem concept [22]. Furthermore, the term innovation ecosystem is suggested to be ideally used in relation to systems that focus on innovation activities (goal/purpose), involve the logic of actor interdependence within a particular context (spatial dimension), and address the inherent co-evolution of actors (temporal dimension) [22]. Therefore, an ecosystem is considered a new structure of economic relationships, which enables the complementaries of production and/or consumption to be contained and coordinated without the need for vertical integration [10].

The complexity related to ecosystems has lately been addressed by categorizing innovation management literature into three broad groups [10]: a business ecosystem stream focusing on a firm and its environment, an innovation ecosystem stream focusing on a particular innovation or new value proposition and the constellation of actors that support it, and a platform ecosystem stream considering how actors organize around a platform. At the same time, a synthesis from the IS literature states that digital platforms are becoming increasingly complex research objects [7;33], and they are sometimes separately treated from and sometimes intimately related to the ecosystem construct or metaphor [20].

\subsection{Emerging ecosystems}

Innovation ecosystems are not an evolved entity; rather, they are designed [19]. Although they are an open social system, they are deliberately designed, and they evolve around a key set of entities, at least at a particular point in time [22]. They do not emerge spontaneously [10], and they are partly the result of deliberate experimentation and engineering from different parties [14]. The emerging of ecosystems has been called birth and expansion [15], pioneering and expansion [16] with processes to nurture it [24].

Although innovation ecosystems are oftentimes presented as separate entities, research emphasizing their structures [12] shows examples of the innovation relationships between the different levels or perspectives, hence providing evidence of the coexistence of ecosystems. For example, ecosystem spanning structures, through exploration of the connections between the enterprise level, growth companies, and start-up companies in Finland, are studied using data on the resource flows between the actors involved [27]. This approach is based on the three levels (micro-meso-macro) of dimensions of social capital [17], corresponding to the similarly named approach to address the resource integration and structurization of service ecosystems, in which levels are contexts that influence one another. The linkages between them are highlighted [32]; innovation ecosystems occur as an integrating mechanism between the exploration of new 
knowledge (the knowledge ecosystem) for value creation and value capturing in business ecosystems. Looking at the economy as a complex space consisting of networks of networks supports this as does the view on innovation ecosystems constituting of special organizational spaces or a sophisticated milieu of actors, assets, and linkages, generated by collaborative activities within and among networks and resulting in functionally inseparable organizational continua of such networks [25].

\subsection{Highlighting modularity, complementarity, and coordination}

Technical modularity contributes to 'theory of ecosystem' [10], as it allows the interdependent components of a system to be created by different producers, with limited coordination required. Therefore, modularity (although not necessarily open interoperability) is seen to create the conditions for the emergence an ecosystem [10]. Complementaries, with examples of "A does not function without B" (described as unique complementaries) or "more A makes B more valuable" (described as supermodular complementaries), allow for some degree of customization, thus explaining the nature of ecosystems.

The theory development has allowed the emergence of the idea of non-controllability: "an ecosystem is a set of actors with varying degrees of multi-lateral, non-generic complementaries that are not fully hierarchically controlled" [10]. Platforms, especially digital ones, are often presented to provide a mediating device between different groups of users [20]. Platforms address the concept of complementary with the concept of two-sided markets, which bring two distinct groups in a relationship; the value for one group increases as the number of participants from the other group increases [6]. This approach corresponds to the role of complementarity in ecosystems. Modularity has also been addressed by IS scholars with traditional governance through an over-arching design hierarchy challenged by a distributed setting, where no single owner owns the platform core and does the dictating [20]. Indeed, digital platforms can be defined as purely technical artifacts in which the platform is an extensible codebase, and the ecosystem comprises third-party modules complementing this codebase [20].

\section{Methodology}

Our quest for understanding the importance of innovation relationships in an emerging ecosystem is based on the need established in the theory section: what ecosystems are and how they operate should be complemented with a consideration of when and why they emerge. We are looking at this within the context of Fintech, as we think it presents a prime example of how technology allows innovationcreating large-scale impacts for users-and how this is not done by a single organization but by larger groups of entities through their innovation relationships. In addition, we have studied the service innovation of Fintech startups [21], and we have explored the Fintech ecosystem [26], as well as retail banking (for example, see [18]), which has given us insights into the transformation taking place and the data sources available for explorative studies.

A tentative theoretical framework for emergence of ecosystems was created in early phases on the process based on our preliminary review. However, the process was abductive. Theoretical understanding was developed alongside analysis of empirical examples [4]. Abductive approach is functional to uncover different logics and deviations in ecosystem emergence among case examples. To understand the emergence, we first looked at the innovation relationships within the Fintech research, and then proceeded toward more detailed perspective of innovation relationships with the help of case examples.

For the purposes of this study, as in many innovation ecosystem mapping exercises, the starting point is boundary specification. This step can be challenging but is needed to understand the scope of the exercise. The parameters and sources for data selection are based on this boundary specification and are driven by the nature and intent of the problem and the questions being asked. The analysis allows us to find answers to the questions by using relevant data. Therefore, we are going to use some of the principles developed for innovation ecosystem visualizations [9;28] in order to communicate how ecosystems emerge and the results in a meaningful way for the intended audience.

\subsection{Context of Fintech}

Traditionally, innovation in the financial sector has mainly focused on technological issues, leaving an open research question on a deeper understanding of the impact of new technologies on services, business models, strategies, and value formation for customers (e.g., [13]). Furthermore, innovations have 
been modifications to existing services by existing and established actors and traditional business models, including proprietary delivery channels; thus far, product-based offerings have retained their position in competition against new entrants.

The rapid rise of Fintech has changed the business landscape in banking and financing, as it requires more innovative solutions. Start-up service providers, search engines, and social networks have expanded their services in the fields traditionally covered by banks. Common examples showing the results of disruptive innovation by Fintech include Paypal (a novel online payment system), WeChat payments (social media-linked payments), Klarna (online payments with micro credit checks), and Holvi (a Finnish bank with no offices, geared mainly toward entrepreneurs). Therefore, Fintech is not only about startups, as established players are active in it, too. For example, Finnish banks have been in the forefront of Internet banking since the 1990s and of mobile banking since the 2000s. Furthermore, Holvi was acquired in 2016 by the Spanish multinational banking giant BBVA, showing the integration between established players and startups.

We used a bibliometric approach and explored research that has been conducted on the topic. With this perspective, we used the Thomson Reuters Web of Science Core Collection (all citation indexes) to run a very basic search on full texts with the search term 'Fintech' between January 1, 1980 and May 24, 2018. It should be noted that prior to this, we defined Fintech, first, as new technologies, such as blockchain, distributed ledgers, artificial intelligence, robotics, open platforms, application programming interfaces, and Internet of things; and, second, as emerging business models developed by new entrants and incumbents offering financial services. Therefore, we used a different approach, as the Fintech ecosystem is usually presented solely to consist of startups in various phases and various groupings. A recent logomap by Venture Scanner where 2,285 Fintech startups have been classified into 16 categories (collectively have raised $\$ 80$ billion in funding). Our view on the Fintech ecosystem is thus aligned with the five elements of the Fintech ecosystem [13], which are (1) Fintech startups, (2) technology developers, (3) government, (4) financial customers, and (5) traditional financial institutions.

\subsection{Context of DLT-based services in two banks in Finland}

Banking delivery channels have been intermediaries already during the physical or branch delivery era. Typically, all banking services, life and non-life insurances, and real-estate services have been delivered through the banking platform. Technologies, such as DLT, blockchain, and application programming interface (API), among others, have accelerated the business model change from traditional vertically integrated value chains into value networks. For the purposes of this study, we define DLT as "a type of database that is spread across multiple sites, countries or institutions, and is typically public. Records are stored one after the other in a continuous ledger, rather than sorted into blocks, but they can only be added when the participants reach a quorum. A distributed ledger requires greater trust in the validators or operators of the ledger" [34, pp.17-18].

For our specific perspective of Fintech, we looked at banking service development and delivery, specifically the banks Nordea Bank and OP (Financial Group), and their innovation relationships. Nordea Bank is an international bank that is present in 17 countries. In Nordic countries, Nordea is the largest retail bank by assets, except in Finland, where it is the second. OP is the largest bank in Finland by assets. Both banks have a long history in Finland (since 1902 for OP and since 1862 for Nordea), so they represent traditional incumbent banks whose business model is proprietary asset based and whose value creation has been performed on end-to-end vertically integrated value chains. Using extensive literature searches, as well as other published materials and company presentations from industry events, we gathered data for the analysis of emerging Fintech. The materials described the innovation relationships, activities, and events that Nordea and OP were engaged in, especially related to DLT, whether hyperledger or blockchain.

\section{Results}

With this paper, the emphasis was on understanding the emergence of Fintech ecosystem. Two complementary perspectives into this are provided: the first looks into the innovation relationships with bibliometric analysis, the second looks into the innovation relationships in the special context of DLT-based services in two major Finnish banks.

\subsection{Innovation relationships in Fintech research: a bibliometric analysis}

Because Fintech is such a recent development, there is still a paucity of studies on its social, 
regulatory, technological, and managerial aspects [13]; we would like to add that overall, studies on Fintech are limited. In comparison to several other topics in business management research, Fintech is rather specific and identifies well its target. We therefore expect that there will be no false positives or papers that include the Fintech term but do not use the term in the same meaning. However, we need to acknowledge that false negatives will take place, as there are works that discuss and present results dealing with the same phenomenon of Fintech but do not use the specific term. A lot of related research is done with key concepts being, for instance, machine learning and finance. The search resulted in 110 items, starting in 2015 (see Figure 1).

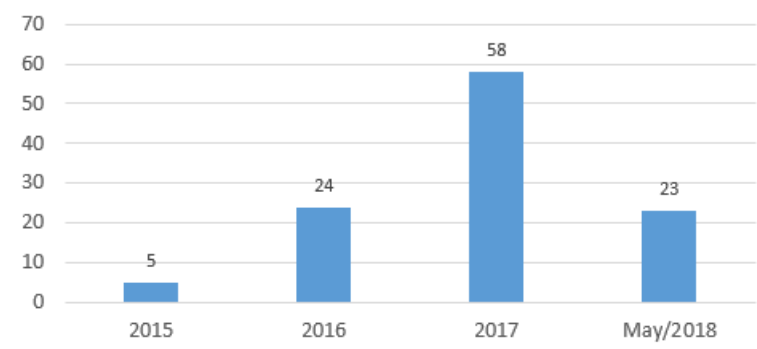

Figure 1. Frequency of Fintech research papers.

As we can see, half of them are from year 2017, which indicates the novelty of the term. Again, the banking and financial world has been taking advantage of the technology for its process automation and speed for decades; for example, advances in Internet banking and mobile banking are most likely not included in the results (because of the search term).

A bibliometric tool, VosViewer, was used to analyze and visualize the key terms, their shifts over time, and the prominent authors (www.vosviewer.com). Because of the very limited amount of data, bibliometric coupling or co-citation analyses do not provide deep insights; the analysis

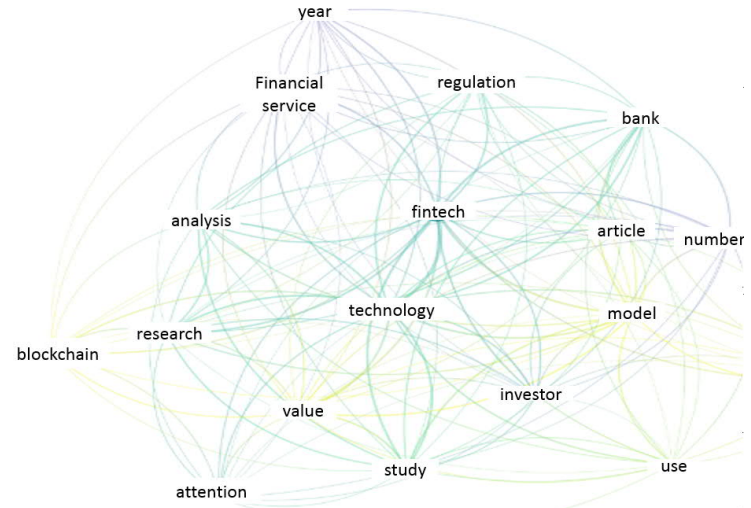

Figure 2. Term map of Fintech research papers. reveals that the field is very scattered, and papers mostly do not cite one another.

On the basis of term co-occurrence in the papers' titles and abstracts, a term map was created to present the dynamics of the Fintech research papers. After the anomalies were dropped, the 10 most mentioned terms in this field were (1) financial service, (2) Fintech, (3) technology, (4) regulation, (5) bank, (6) investor, (7) use, (8) attention, (9) financial industry, and (10) blockchain. As can be seen with the color coding (Figure 2), the emphasis was on terms such as technology, attention, investor, bank, and financial service (indicated by the blue color). Recently, the terms blockchain, value, model, and financial industry have received more focus (indicated by the yellow color).

\subsection{DLT-based services in two major Finnish banks}

The analysis of relevant data about the innovation relationships of Nordea and OP led us to a number of Fintech ecosystems. Based on the typology presented by [10], the ecosystems that we encountered were placed into the three bins. Those concentrated on innovation were categorized as innovation ecosystems, those who were centered on the firm were categorized as business ecosystems, and those who focus on platform were categorized as platform ecosystems.

Both Nordea and OP are participating in global development activities. Both have been members of Corda/R3, since 2015. Corda is a global network to develop distributed ledger technologies (DLT). Nordea is also a member in we.trade platform, which is a European wide ecosystem to develop DLT-based trade finance platform for international importing and exporting business. We.trade in turn, uses Hyperledger, which is a global open source innovation ecosystem to advance cross-industry blockchain technologies. OP has chosen to become a member of Marco Polo network, which is a European wide innovation ecosystem to develop DLT-based trade finance platform similar to we.trade. Marco Polo trade finance solution uses for its part Corda as the technical platform.

Again, reflecting the ambiguity of the ecosystem term, we saw that the ecosystems are often described more with networks (Table 1.). For example Corda is described as an ecosystem but with words: "What started as an alliance of nine financial institutions in 2015 committed to delivering the next generation of blockchain technology has evolved to a network of over 200 financial institutions, buy-sides, insurance companies, technology companies, software firms, 
Table 1. Innovation ecosystems: global development

\begin{tabular}{|c|c|c|c|}
\hline Ecosystem & R3/CORDA [a] & we.trade [b] & Marco Polo [c] \\
\hline WHAT & $\begin{array}{l}\text { An open source software project: } \\
\text { Distributed ledger platform designed } \\
\text { specifically for the financial sector. } \\
\text { Over } 200 \text { members including } 80 \\
\text { financial institutes }\end{array}$ & $\begin{array}{l}\text { A joint-venture company } \\
\text { owned by } 9 \text { European } \\
\text { banks }\end{array}$ & $\begin{array}{l}\text { a Trade Finance Platform } \\
\text { built on an interoperable } \\
\text { business network by open } \\
\text { Application Programming } \\
\text { Interfaces (APIs) and } \\
\text { blockchain technology }\end{array}$ \\
\hline HOW & $\begin{array}{l}\text { Global network of partners to } \\
\text { develop innovative apps for finance } \\
\text { and commerce on blockchain } \\
\text { platform }\end{array}$ & $\begin{array}{l}\text { Innovation with } \\
\text { Hyperledger and IBM }\end{array}$ & $\begin{array}{l}\text { With trade finance } \\
\text { technology firm TradeIX, } \\
\text { R3, and a network of over } \\
\text { twenty financial institutions }\end{array}$ \\
\hline WHY & $\begin{array}{l}\text { To allow businesses transact directly } \\
\text { between each other }\end{array}$ & $\begin{array}{l}\text { To develop blockchain } \\
\text { trade platform for } \\
\text { commercial clients and } \\
\text { their banks }\end{array}$ & $\begin{array}{l}\text { To fill the need of pre- and } \\
\text { post-shipment trade finance } \\
\text { solutions }\end{array}$ \\
\hline WHEN & $\begin{array}{l}\mathrm{R} 3 \text { was established in } 2015 \text {, Corda } \\
\text { was created in } 2016\end{array}$ & 2017 & 2017 \\
\hline $\begin{array}{l}\text { Nordea } \\
\text { Participation }\end{array}$ & Since October 2015 in R3 & 2017 & - \\
\hline $\begin{array}{l}\text { OP } \\
\text { Participation }\end{array}$ & Since December 2015 in R3 & - & 2017 \\
\hline
\end{tabular}

[a] https://www.corda.net/; https://www.corda.net/wp-content/uploads/2018/05/corda-platform-whitepaper.pdf; https://docs.corda.net/_static/corda-technical-whitepaper.pdf

[b] https://www.we-trade.com/, https://www.we-trade.com/pdf/datasibos_wetrade presentation-db776b3070.pdf

[c] https://www.marcopolo.finance/

central banks, regulators and exchanges on six continents." (https://www.r3.com/ecosystem/). As such, Corda was categorized as an innovation ecosystem. Similarly, we.trade and Marco Polo were both seen as innovation ecosystems as it concentrates on innovation around hyperledger and blockchain, though they both are aiming for a business model and gearing towards becoming a platform. With code sharing, they all combine the technical competences of their respective members into modular formats that can be used. With mutual interoperability, the complementaries are then intented to support the overall innovation. Coordination takes place without hierarchical structures within the network, with plans of smart contracts and other technological solutions to support interactions and transactions.

To take advantage of the new technology that is being developed, tested and standardized at the innovation ecosystems, both banks have created organizational entities aimed at improving their own innovation processes, for their local development, allowing for flows of resources from outside of the company. Nordea has established a hub for open banking developer community called Nordea For Developers Portal, which is an open banking project initiated by the execution of European Payment Service Directive (PSD2). In the Portal, Nordea offers APIs into accounts and payments information for third party developers to build new financial solutions. OP's answer to this is called OP Developer. It is a hub for open banking developer

community enabling third parties, such as FinTech startups or OP's existing partners and major customers to make use of OP's services in the development of their own applications and services. They were both established in 2017 (Table 2).

Both Nordea for Developers Portal and OP Developer were categorized as business ecosystems because they clearly focus on the firm, which is also indicated by their names both containing the company name. The modular resources offered by open innovation (external entities) are seen complementary for own resources. The coordination takes place with the community and its rules as well as with APIs (application programming interfaces). Again, the ambiguity can be noted as these are described as communities. A novel service, has been developed in Finland-with participation of both Nordea and OP (as well as other locally operating banks and real estate players). The new service provides a digital trading system for housing market managed by a start-up firm Tomorrow Labs (Table 3). This initiative uses Corda-platform to execute so called "smart contract", which means that in real estate trade, ownership, collaterals, and information for all parties including authorities is transferred at the same time as the payment transaction from the buyer to the seller. Hence, it replaces an old system where buyer had to physically move the ownership collateral documents from one location to another 
Table 2. Business ecosystems: local development

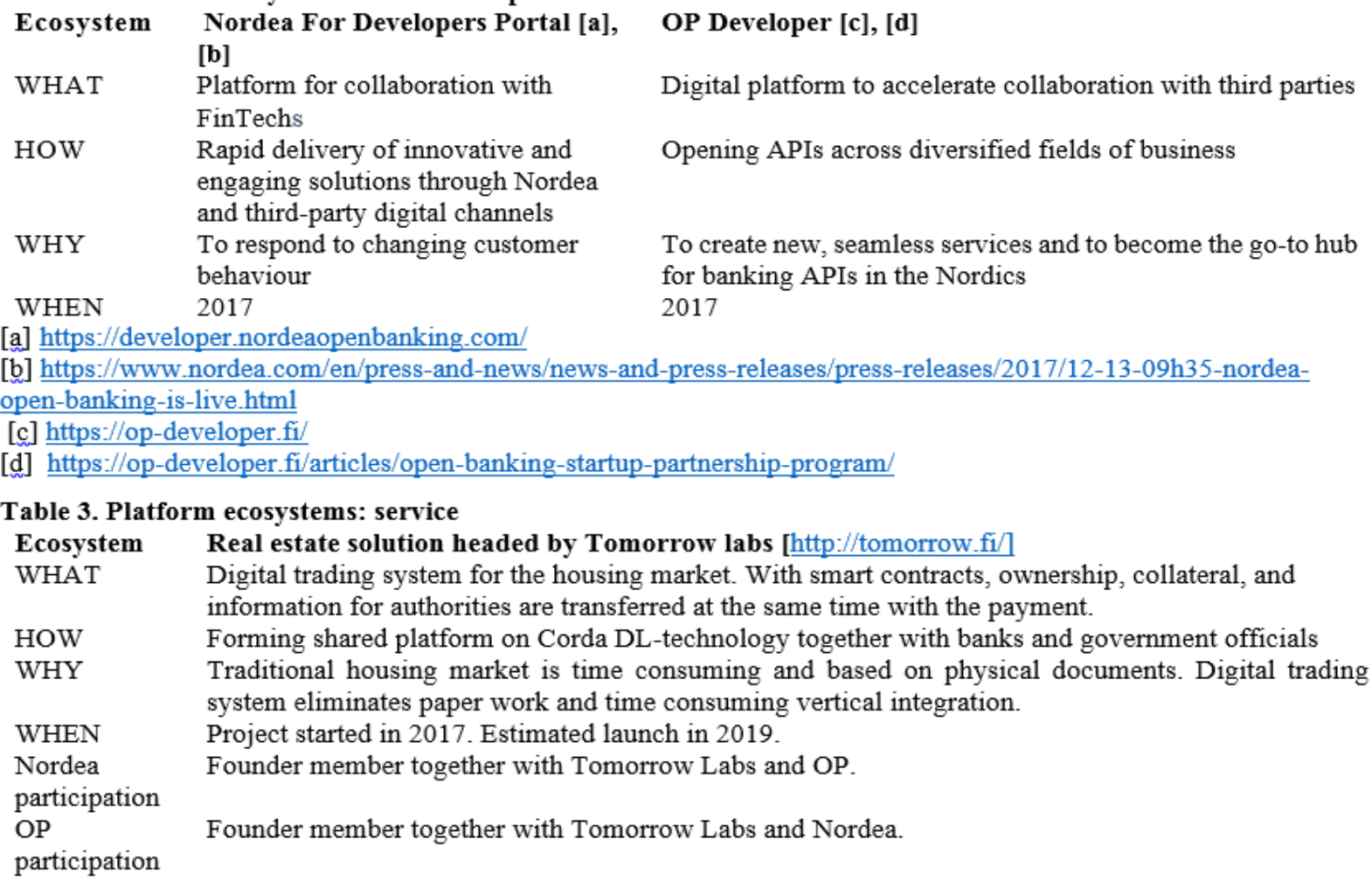

In the digital trading system for housing market, the aggregation of service components (modular services offered by multiple service providers) needed in real estate transaction is not a sum of fixed buyer-supplier relations. Instead, in a service offered by an ecosystem, the customer can choose from the selection of components supplied by each participant, in a way that is complementary for his/her needs. Furthermore, it is possible that the customer can choose the combination as well. For example, in our real estate example, the customer is not tied to one bank, but can select and form own combinations of financial services needed on the process. The customer may also include or exclude some services on the platform e.g. by using self-service. In other words, service in ecosystem does not fit into the traditional firm-supplier relationship pattern. The discrete parts of production process are referred to as "thin crossing points" [2]. In the case example of digital trading system for housing market, the thin crossing points are Application Programming Interfaces (APIs), which connect the needed parts into coherent service, with no need for additional coordination.

\section{Discussion}

The quest for understanding the emergence of ecosystems was at the core of this paper. Hence, we contribute to the nascent literature of ecosystems, as it has been established that emergence of ecosystems needs to be studied in order to better understand the phenomenon (similar approach, see [3]).

The case examples of the innovation relationships of Nordea and OP banks supported the noted challenges of the ecosystem concept, as the terms networks, communities and platforms were interchangeable used with it. The implications of semantics are present for both academics as well as practitioners. For academics, we propose highlighting the elements of modularity, complementarity and coordination with the shared goal, and making those explicit in the descriptions of ecosystems, as those are the elements that separate ecosystems from networks and communities. For practitioners, we would like to emphasize the importance of understanding the need of those elements, however, always complementing the ecosystem level approach with the needs of individual actors. The development activities can then be designed better and ecosystems managed better. 


\subsection{About innovation relationships in Fintech research}

The innovation relationships of Fintech research were analyzed with bibliometric analysis, resulting to a visualization of "what" related to Fintech ecosystem. Our analysis shows that Fintech is more than startups. The key terms from the analysis revealed that Fintech literature also addresses technology such as blockchain, but also use and value for the customer, and the role of regulation, bank and investor (Figure 3.) Hence, it validated our approach to Fintech, simultaneously supporting the boundary specification of the specific case example of looking into the two major Finnish banks and their service development with DLT.

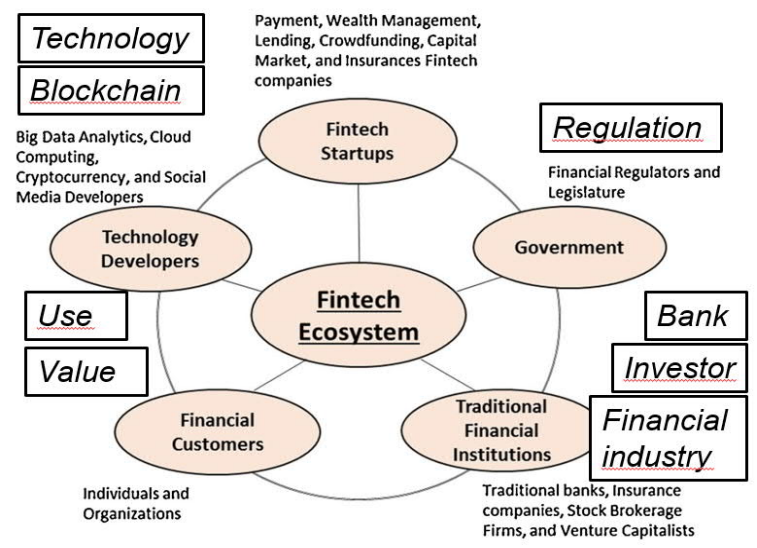

Figure 3. The results of bibliometric research superposed on five elements of Fintech ecosystem.

The analysis of the specific ecosystems also shows the importance of multiple actors in the Fintech ecosystems. For example, the founding members of the innovation ecosystems were largely banks. Also authorities, Fintech startups and technology developers were actively involved in those. The role of Fintech startups was emphasized in the business ecosystems of banks, as they were seen to provide complementary resources for the banks. In platform ecosystems, also multiple actors were present.

\subsection{About innovation relationships in DLT- based services}

The case examples from Nordea and OP banks and their connections to various Fintech ecosystems shows that there is a reason for those ecosystems to exist and why actors join them. The importance of a shared goal- the existence of clear overarching goal and a sense of direction, which allows the ecosystem members to bond, enables collaboration and shapes the focus [11] - was clearly present in all of the ecosystems. The ecosystems descriptions revealed the ecosystem level goals, which to some extend were complementary for the banks. For example, the reason that both banks were participating in $\mathrm{R} 3 /$ Corda was to develop and get the new technology of DLT for their own current and future operation.

Further, we found that the defining elements of ecosystems were addressed in all of studied ecosystems. Modularity and complementarity were explained as both the reason for sharing resources but also as the means for sharing resources. Coordination was addressed to highlight the attractiveness of the ecosystem, making it easy for members to join. Hence, technological modularity was seen to allow for interdependent components to be produced by different producers requiring limited coordination, exactly as is been argued [10]. The case example supports the classification of ecosystems into the three streams, with Nordea and OP taking part in all of them. From 2015 to 2018, all of the three forms of Fintech ecosystems have taken place. Innovation ecosystems were seen to be about global development, and acted as community-hubs with shared activities. Business ecosystems were seen to be about local development, with bank-as-a-hub, and much of the activities still being proprietary. Platform were about novel service, with startups as hubs, again with shared activities.

Though the data about the Fintech ecosystems that Nordea and OP participate in could be presented in table format separately for each of them, the network visualization (Figure 4) exhibits how ecosystems are connected, creating a "network of networks". This brings forth the complexities of innovation relationships in even such a specific perspective of two major Finnish banks and their service development with DLT. In addition, this shows the emergence of three streams of ecosystems taking place simultaneously, with resource flows between them.

In a way, banks have been platforms for a wide array of services since the physical branch era. Banking services, life \& non-life insurances, and real estate services have been delivered through the branch platform. Value creation has been asset based and performed on end-to-end vertically integrated value chains. Now in ecosystems, value is formed by value networks based on the customer needs and goals, and assets have value only when embedded into customer's own value formation. It is yet to see how fast systemic, platform-based services evolve. However, proprietary and asset-based financial transactions do not solve the challenge of 


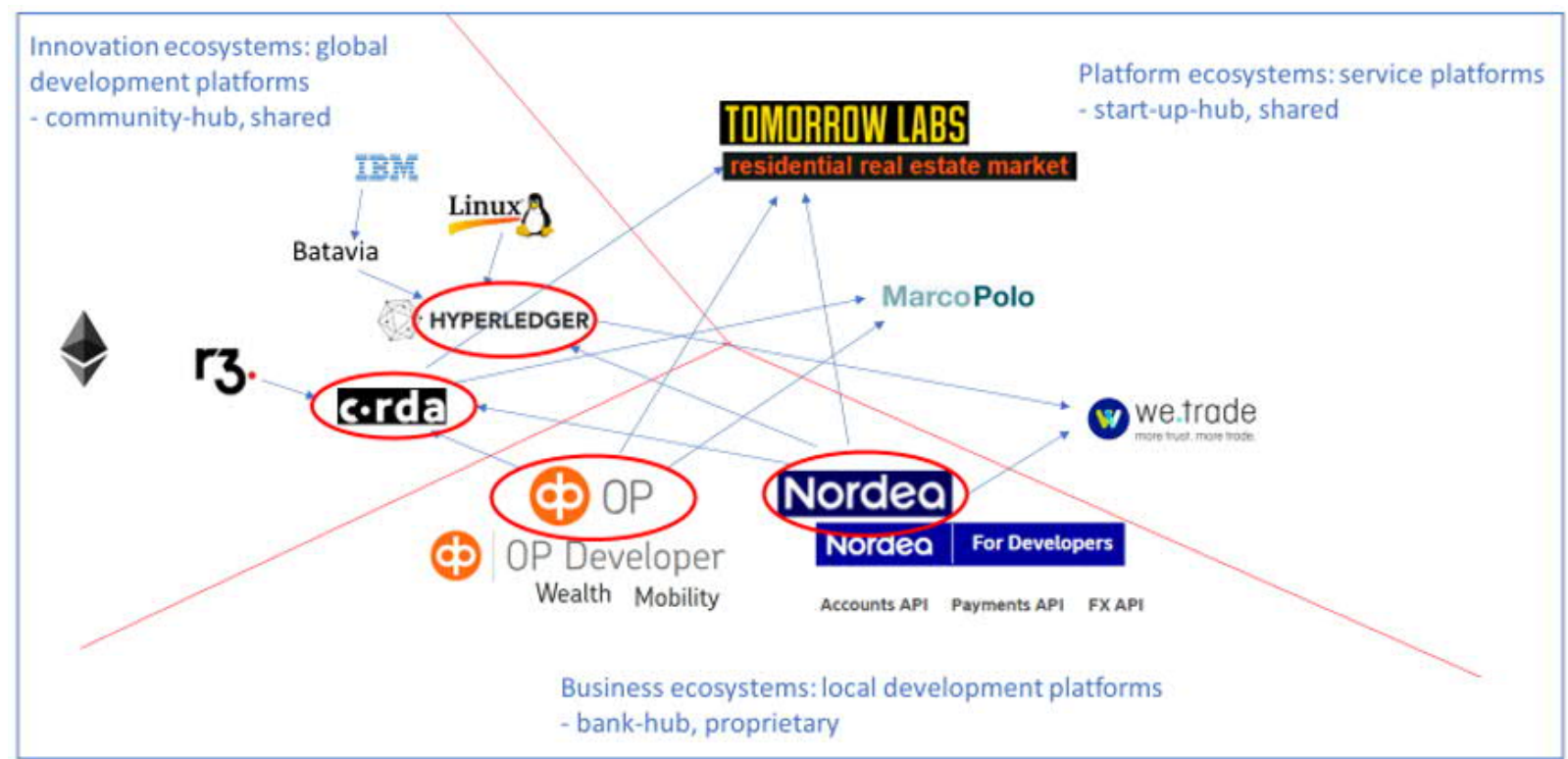

Figure 4, Three groups of Fintech ecosystems linked by innovation relationships of Nordea and OP banks

coordinating customer's value formation as well as contextually relevant interactions of an entire network. For the platform ecosystem, the whole network of actors is needed. Fintech is seen to answer this.

Our research highlights that institutional logic and business models are changing. Established players are participating in this change with their innovation relationships spanning multiple arenas, though some participants of the financial services industry see the boom in Fintech as a threat to traditional banking industry, and market indeed shows growing competition from nonfinancial institutions [23]. Seeing the promise and the flows of venture capital investments, governments around the world have devised policies and regulations to support Fintech development [35].

To conclude our implications about two Finnish banks in their platform and ecosystem development, we notice how the role of a traditional bank changes from proprietary service provider into larger service systems provider on platforms and by ecosystems. First, this takes place as traditional vertically integrated delivery and supply-chains are displaced by real-time service systems where one transaction triggers other services, transactions, or data inputs. Secondly, the role of financial services turns increasingly into commodities. If the systemic service is on a higher level on the customers need hierarchy, components like payments, loans, and collaterals are easily replaced; in other words, they are highly generic complementaries [29]. Thirdly, the role of the customer to define the final service is getting more important, i.e. the dominancy of the bank that has been descriptive in traditional bank-customer relationship turns in ecosystems into customer's dominancy.

\section{Conclusion}

In this paper, we explored the emergence of ecosystems within the boundary specification of Fintech. We demonstrated this showing the relationships of Fintech research with bibliometric analysis and with a case example about two of the biggest retail banks in Finland and their innovation relationships in developing Distributed Ledger Technologies (DLT) and services that are formed on DLT-platforms.

The bibliographic analysis presented how research has approached the emerging Fintech ecosystem with key words that go beyond startups and present a role for other players. Accordingly, we showed how established players-our case example of Nordea and OP banks - have multiple innovation relationships and can be seen to be part of the emerging Fintech ecosystems, corroborating the three broad groups of ecosystems identified [10]: business ecosystems, innovation ecosystems, and platform ecosystems. Our case examples were involved in all three kinds of ecosystems in their businesses. We can also see connections to form an entirety between the ecosystems. Both banks are members on open source software project to develop Distributed Ledger Technology. This technology is used in local markets to develop and offer new services in the platform 
ecosystem where several service providers and their services are connected by a modular architecture. Nordea and OP have also formed proprietary developer communities. These business ecosystems accelerate collaboration with third parties. Thus, there seems to be a clear connection between three ecosystems firms of both banks to develop new platform economy services.

\section{References}

[1] Ahuja, G., Soda, G. and Zaheer, A. 2011. The genesis and dynamics of organizational networks, Organization Science, 23(2), 443.448.

[2] Baldwin, C. Y. 2007. Where do transactions come from? Modularity, transactions, and the boundaries of firms. Industrial and corporate change, 17(1), 155-195.

[3] Basole, R. C. and Patel, S. S. 2018. Transformation Through Unbundling: Visualizing the Global FinTech Ecosystem. Service Science. vol. 10, no. 4, pp. 1-18.

[4] Dubois, A., \& Gadde, L. E. 2002. Systematic combining: an abductive approach to case research. Journal of business research, 55(7), 553-560.

[5] Eickhoff, M., Muntermann, J., \& Weinrich, T. (2017). What do FinTechs actually do? A taxonomy of FinTech business models. ICIS2017.

[6] Evans, P. 2003. Some Empirical Aspects of Multi-Sided Platform Industries, Review of Network Economics

[7] Gomber, P., Koch, J. A., \& Siering, M. (2017). Digital Finance and FinTech: current research and future research directions. Journal of Business Economics, 87(5), 537-580. [8] Heinonen, K., \& Strandvik, T. 2017. Reflections on customers' primary role in markets. European Man. Jour.

[9] Huhtamäki, J. 2016. Ostinato Process Model for Visual Network Analytics: Experiments in Innovation Ecosystems. Doctoral Thesis. Tampere University of Technology.

[10] Jacobides, M. G., Cennamo, C., \& Gawer, A. 2018. Towards a theory of ecosystems. Strategic Man. Journal.

[11] Järvi, K., Almpanopoulou, A., \& Ritala, P. 2018. Organization of knowledge ecosystems: Prefigurative and partial forms. Research Policy.

[12] Järvi, K and Kortelainen, S 2017, Taking stock of empirical research on business ecosystems: a literature review' International Journal of Business and Systems Research, vol 11, no. 3, pp. 215-228.

[13] Lee, I. and Shin, Y. J. 2018. Fintech: Ecosystem, business model, investment decisions and challenges. Business Horizon, 61(1): 35-46.

[14] McPhee, C., Dedehayir, O., \& Seppänen, M. 2017. Editorial: Platforms and Ecosystems (September 2017). Technology Innovation Management Review, 7(9): 3-5.

[15] Moore, J. F. 1993. Predators and prey: a new ecology of competition. Harvard business review, 71(3), 75-86.

[16] Moore, J. F. 1996. The death of competition: leadership and strategy in the age of business ecosystems (p. 297). New York: Harper Business.

[17] Nahapiet, J. and Ghoshal, S. 1998. Social capital, intellectual capital and the organizational advantage, Academy of Management Review, 23, 242-266.
[18] Nätti, S. and Lähteenmäki, I. 2016. The evolution of market orientation in Finnish retail banking-from regulation to value creation. Journal Management \& Organizational History, 11(1).

[19] Oh, D. S., Phillips, F., Park, S., \& Lee, E. 2016. Innovation ecosystems: A critical examination. Technovation, 54, 1-6.

[20] de Reuver, M, Sørensen, C \& Basole, RC 2017, 'The digital platform: a research agenda' Journal of Inf. Tech.

[21] Riikkinen, M., Still, K., Sarajärvi, S. \& Kallio, K. 2016. FinTechs as service innovators: analyzing the components of innovation. ISPIM, Porto, 17-22 June.

[22] Ritala, P., \& Almpanopoulou, A. 2017. In defense of 'eco' in innovation ecosystem. Technovation, 60, 39-42.

[23] Romānova, I., \& Kudinska, M. 2016. Banking and Fintech: A Challenge or Opportunity?.In Contemporary Issues in Finance: Current Challenges from Across Europe (pp. 21-35). Emerald Group Publishing Limited.

[24] Rong, K., Wu, J., Shi, Y., \& Guo, L. 2015. Nurturing business ecosystems for growth in a foreign market: Incubating, identifying and integrating stakeholders. Journal of International Management, 21(4), 293-308

[25] Russell, M.G. and Smorodinskaya, N.V. 2017. Leveraging complexity for ecosystemic innovation, Technological Forecasting \& Social Change.

[26] Still, K., Huhtala, T., \& Saraniemi, S. 2016. FinTechs as Business and Innovation Ecosystems. A paper presented at ISPIM Summit, Kuala Lumpur, Malaysia, Dec 2016.

[27] Still, K., Huhtamäki, J., Russell, M.G., Basole, R.C., Salonen, J. and Rubens, N. 2013. Networks of innovation relationships: multiscopic views on Finland. Proceedings of the XXIV ISPIM Conference, Finland, 16-19 June.

[28] Suominen, A., Seppänen, M., \& Dedehayir, O. 2018. Innovation systems and ecosystems: a review and synthesis. European Journal of Innovation Management.

[29] Teece, D. J. 2018. Profiting from innovation in the digital economy: Enabling technologies, standards, and licensing models in the wireless world. Research Policy.

[30] Thomas, L. and Autio, E. 2012. Modeling the ecosystem: a meta-synthesis of ecosystem and related literatures. DRUID 2012, Copenhagen, Denmark.

[31] Townsend, A., Pang, A.S.-K., Weddle, R. 2009. Future Knowledge Ecosystems: The Next Twenty Years of Technology-led Economic Development. IFTF SR-1236.

[32] Valkokari, K. 2015. Business, innovation, and knowledge ecosystems: How they differ and how to survive and thrive within them. Technology Innovation Management Review, 5(8).

[33] Vargo, S.L. and Lusch, R.F. 2016. Institutions and axioms: an extension and update of service-dominant logic. Journal of the Academy of Marketing Science, 44(4), 5-23. [34] Walport, M. G. C. S. A. 2016. Distributed ledger technology: Beyond blockchain. UK Gov. Off. for Science. [35] Wonglimpiyarat, J. 2017. FinTech banking industry: a systemic approach. foresight, 19(6), 590-603. 